\title{
HAZOP Analysis and Research of Temporary Acid Adding System for High-Discharge Waste Liquid
}

\author{
Zan Guo ${ }^{1 D},{ }^{1,2}$ Shuliang Zou ${ }^{1 D},{ }^{1,2}$ Wenge $M a,{ }^{3}$ and Haiyin Dai ${ }^{3}$ \\ ${ }^{1}$ University of South China, School of Resource Environmental and Safety Engineering, Hengyang 421000, Hunan, China \\ ${ }^{2}$ University of South China, Hunan Provincial Key Laboratory of Emergency Safety Technology \\ and Equipment for Nuclear Facilities, Hengyang 421000, Hunan, China \\ ${ }^{3}$ Sichuan Environmental Protection and Engineering Co., Ltd., CNNC, Guangyuan 628017, Sichuan, China \\ Correspondence should be addressed to Shuliang Zou; zousl2013@126.com
}

Received 11 November 2020; Revised 11 January 2021; Accepted 10 February 2021; Published 23 February 2021

Academic Editor: Peter Ivanov

Copyright (c) 2021 Zan Guo et al. This is an open access article distributed under the Creative Commons Attribution License, which permits unrestricted use, distribution, and reproduction in any medium, provided the original work is properly cited.

To prevent the formation of salt from fission products of high-level radioactive liquid wastes (HLWs), a certain amount of acid is added to maintain the acidity of liquid waste. This study analyzes the accidents associated with the addition of acids in a factory by using the hazard and operability analysis (HAZOP), while elucidating the corresponding defects and risks of this approach. By improving the design of the system, the possibility of an accident is significantly reduced. This study can provide guidance for adding acids to treat other high-level waste liquids.

\section{Introduction}

Recently, the treatment and disposal of high-level radioactive liquid wastes (HLWs) have become essential but difficult task for radioactive waste management $[1,2]$, thereby restricting the sustainable development of the industries. Storage of HLWs can be considered as an intermediate step between post-treatment and solidification [3]. Moreover, solidification of liquid waste becomes progressively easier, with the fission products in the liquid waste being cooled continuously. However, an increased storage time leads to a larger storage volume as well as higher investments and operating costs $[4,5]$. The liquid storage periods generally depend on numerous factors and national policies; consequently, waste solidification can take just a few months, several years, or even decades [6-8]. Considering that the nature of HLW is different from that of conventional liquid waste, its storage can lead to major accidents [9]. During the long-term storage of HLWs, waste acid solutions continue to evaporate; however, the rate of evaporation is slow. Generally, waste liquor is stored for extremely long periods; therefore, its concentration can decrease over time, resulting in the separation of liquid wastes and nitrate enrichment. Precipitated nitrates tend to crystallize and contain plutonium, which increases the risk of accidents and facilitates localized corrosion of storage tanks. Therefore, essential and appropriate safety measures must be implemented [10], based on the characteristics of HLW.

In decades of engineering practice, although no accidents have occurred in China's HLWs due to acid addition, some phenomena indicate that the acid addition system has hidden dangers. Therefore, it is an urgent problem to properly analyze the acid adding system of HLW, which is of great significance to the safe storage, ecological environment, and public society of HLW.

\section{Analysis and Application of the HAZOP Method}

2.1. An Introduction to the HAZOP Method. Hazard and operability analysis (HAZOP) is a hazard identification technique developed using system engineering [11]. As a structured method for safety analysis method, HAZOP systematically identifies various potential deviations from the design purpose; subsequently, it analyzes the causes of each deviation and evaluates the corresponding 
consequences. Compared with failure mode and effects analysis, fault tree analysis, and other methods, HAZOP can more comprehensively identify the risks and design defects associated with a given system. HAZOP has been widely applied in chemical processes [12] and electronic technologies [13], thereby establishing standardized guidelines for its application [14]. These guidelines include an analytical process and specific keywords to describe deviations from the design purpose. These words form the basis of the HAZOP analysis and are used to summarize all the cases where deviations occur.

The analysis process is shown in Figure 1 [11]. HAZOP analysis is based on meetings wherein a multidisciplinary team analyzes the hazards and operational issues of a particular process. The primary aim of the HAZOP analysis is to determine the important steps of the process, which are called "analysis nodes," or process units, or operational steps. For determining each "analysis node," the HAZOP analysis group assumes the process (state) parameters used for normal operation as standard values to analyze the changes (deviations) in process (state) parameters during the process; subsequently, the causes, consequences, and preventive measures associated with deviation failure are analyzed [15]. The risks and hazard factors associated with the device or production process are studied, and corresponding measures are taken to prevent the consequences of the abovementioned changes and deviations.

2.2. HAZOP Analysis Steps. According to the references, HAZOP can be divided into three steps: preparation analysis, completion analysis, and preparation of analysis results report. The process conditions deviating from the design are analyzed and discussed simultaneously by various professionals such as automatic control, field operation, process, and equipment operators. The main difference between HAZOP analysis and other safety assessment methods is that while other safety assessment methods can be performed by one person, HAZOP analysis must be completed by a team composed of various professional technicians and managers in the production process.

The HAZOP analysis method is performed using in the following steps; the analysis process is shown in Figure 2: (1) analysis of preparation; (2) completion of analysis; (3) preparation of the analysis report.

Figure 2 shows the entire process of the HAZOP analysis. It is important to note that these steps can be performed alternately. For instance, after the analysis team determines an analysis node (but not all of them), the results can be submitted to the designer, who can then proceed to make changes to the original design.

\section{Introduction to Storage Tank of HLW}

Concentrates produced by evaporation and denitrification of HLWs are highly radioactive $[17,18]$, while causing significant heat production and corrosion on decaying. The concentrated liquor of HLW is generally stored in a large stainless steel storage tank [19]. To safely store HLWs, storage tanks with four safety barriers are used, namely, the stainless steel storage tank itself, stainless steel cladding, reinforced concrete equipment room, and clay adsorption layer (Figure 3). These four safety barriers will effectively isolate the HLW from the human environment. However, these tanks are just a temporary measure for storage. HLWs also contain fission products, such as ${ }^{137} \mathrm{Cs}$ and ${ }^{90} \mathrm{Sr}$, which take at least five or six hundred years to be stabilized [20,21]. Their mean activity concentrations rang from $3.7 \times 10^{13}-1.1 \times 10^{14} \mathrm{~Bq} / \mathrm{L}$; therefore, their long-term storage is highly unsafe.

During the long-term storage of HLWs, it takes a long time for the acidity of the liquid waste to drop below the specified limit [22]. This is because waste acid solutions will continue to evaporate at a slow rate, with the storage time of the waste liquor being very long; consequently, this may decrease the acid concentration of waste liquor, resulting in the separation of liquid waste separation and nitrate enrichment. Moreover, two to three additional acids are added at most during the entire storage period of the liquid waste. Therefore, there is no fixed system used for adding acid, and it is only constructed temporarily whenever acid is needed.

\section{Structure of the Temporary Acid System}

Figure 4 structures the temporary acid system; it contains the acid tanker, produced water, pipelines, valves, flow meters, and U-shaped pipelines. The specific process diagram is shown in Figure 4.

According to Figure 4, the temporary pipeline is supported by a bracket and maintains a five-degree tilt from left to right; stainless steel flanges are observed on the attachments between the valves, tee, and pipes. The parameters and models of each pipeline equipment are shown in Table 1 .

The right side of the temporary acid system begins from the top of the standby instrument and presses through the HLW storage tank; it submerged no more than $10 \mathrm{~cm}$, and a valve is set on the cover plate to control the acid flow into the tank. The acid tanker and produced water are contaminated by the tee junction at the left side of the temporary adding acid system, and valves are used to control the acid and water contents in the pipe. Subsequently, an electromagnetic flow meter is used to estimate the acid content at the back of the tee junction.

For preventing the escape of aerosols while adding acid, we need to set up U-shaped pipelines that comprise an acidproof stainless steel metal hose; the left side of the tube and the right side of the valve 3 are attached by a flange. After successful construction of the temporary acid system, it is confirmed that the pipeline and various joint seals are in good condition, while all valves are closed.

\section{Cause Analysis for Parameter Deviations}

The accidents that may occur in the temporary acid system used for treatment and disposal of high-discharge liquid wastes, include countercurrent flow, aerosol extravasation, and acid leakage. According to the guide words, we can determine and analyze the deviations in the HAZOP analysis model, find out the causes and consequences of the 


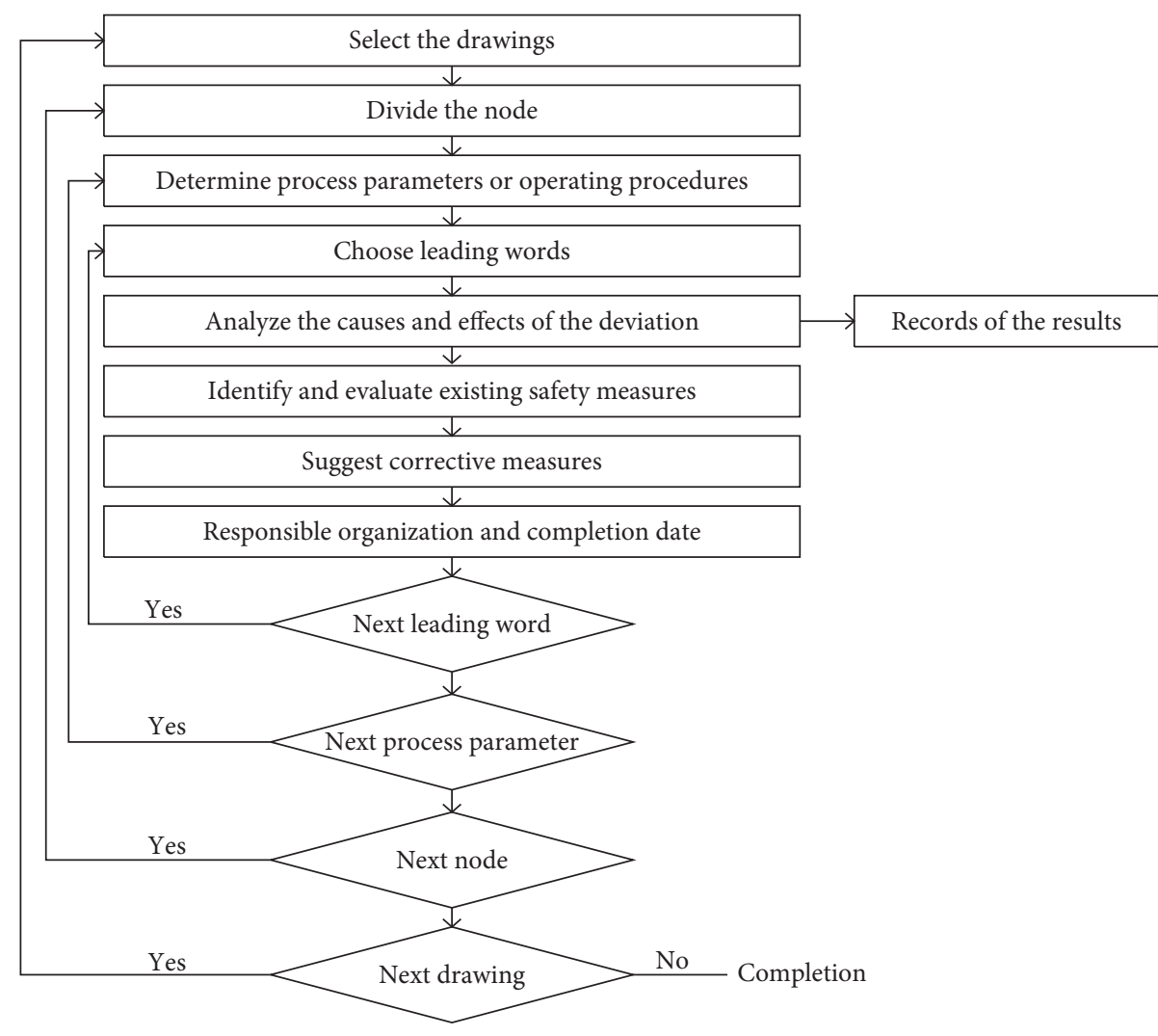

Figure 1: The analysis flow chart of HAZOP.

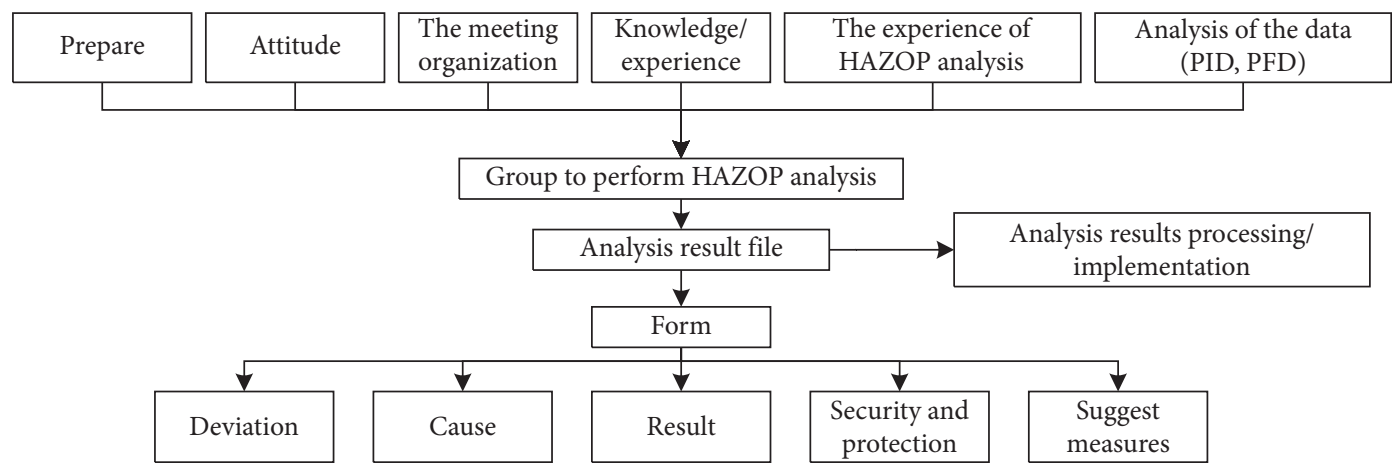

Figure 2: HAZOP analysis process [16].

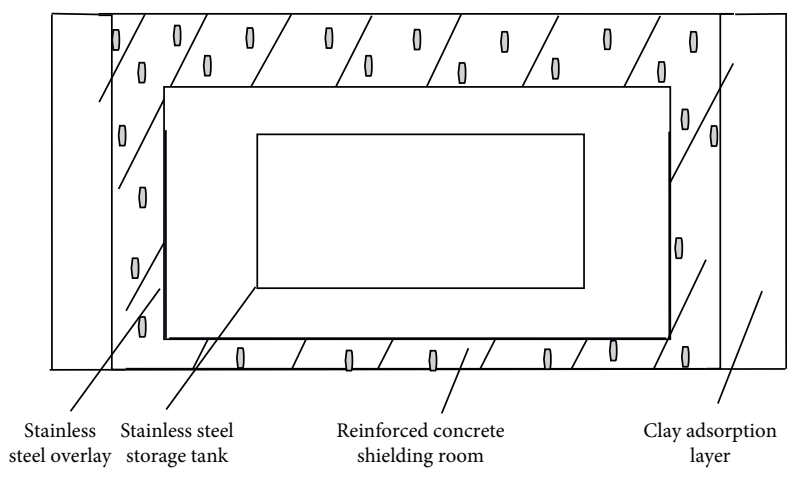

FIgURE 3: Four protective layers for high-level liquid waste storage tanks. 


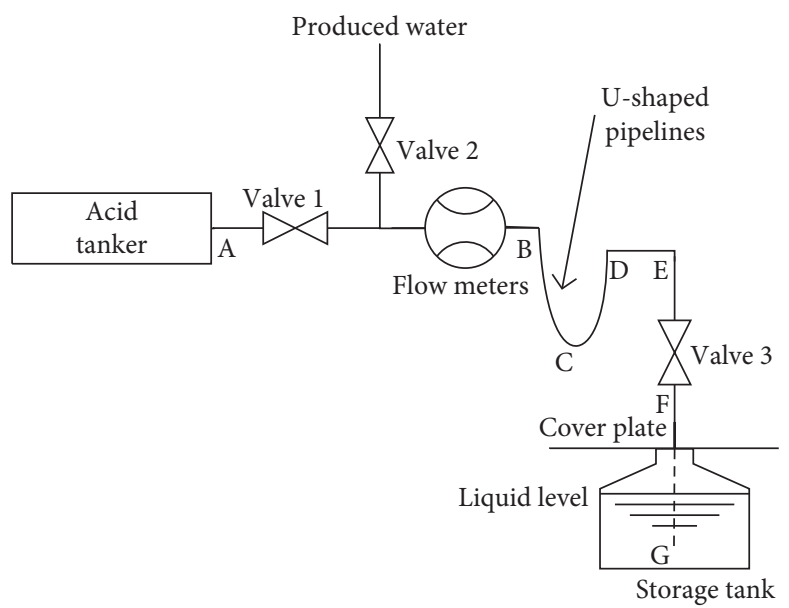

FIGURE 4: Schematic diagram of temporary acid adding system for high-discharge waste liquid.

TABLE 1: Main equipment and equipment parameter table.

\begin{tabular}{lcc}
\hline No. & Device name & Main technical parameter \\
\hline 1 & Acid tanker & $30 \mathrm{~m}^{3} / \mathrm{h}$ \\
2 & Acid-proof stainless steel globe valve (valve 1, 2, and 3) & J41W-16P DN20 \\
3 & Electromagnetic flow meter & HP-LDE20 DN20 \\
4 & AB period of stainless steel pipe & DN20, 4000 mm long \\
5 & BCDE acid-proof stainless steel metal hose & DN20, the vertical height of BC is 200 mm \\
7 & FG period of stainless steel pipe & DN20, 3500 m long \\
8 & Stainless steel tee & DN20 \\
9 & Stainless steel flange & DN20 \\
\hline
\end{tabular}

deviations, and formulate corresponding safety control measures. The analysis results are shown in Table 2.

5.1. Flow: Countercurrent Flow. Main causes resulting in accidents are countercurrent flow of high-discharge liquid waste including compressed air addition, nonstandard air filter, and defective high-pressure fan, which lead to a positive pressure in the storage tank. Since valve 3 and valve 2 are closed, the end of the acid-containing pipe goes directly into the high-discharge liquid wastes.

The ventilation system for the temporary acid process is shown in Figure 5. To prevent the reflux of HLW, the pressure exerted by the HLW inside the tank must be negative in normal state; however, the process of stirring the compressed air to add acid induces a positive pressure inside the storage tank. Although there are high-pressure fans to open the tank for releasing smoke and consequently overcome the positive pressure induced by the compressed air, there is a possibility that the tank will experience a positive pressure, which could lead to the reflux of HLWs.

5.2. Level (Liquid): Aerosol Extravasation. Accidents occurring due to aerosol extravasation are observed under the following conditions: the end of the acid-containing pipe is inserted too deep into the liquid, the liquid level in the U-tube is insufficient, and valve 2 is not closed.

When the acid flows into the liquid waste, a large amount of heat tend to be released; this increases the temperature of the high-discharge liquid waste, leading to its rapid evaporation. In particular, the high-discharge liquid waste at the end of the acid-containing pipeline will evaporate quickly, and the aerosol generated by evaporation will enter the DG pipe. Accordingly, the temperature of the DG pipe will also rise, that is, the temperature of the gas and the amount of gaseous substances in the DG pipe increase simultaneously. When the U-shaped pipeline is broken, the gas in the DG pipe will continuously enter the $A B$ pipe through the $U$ shape pipeline in the form of bubbles. Since the $A B$ pipe comprises the higher slope of end $\mathrm{A}$ and the lower slope of end $B$, the bubbles will flow to end $A$, thus polluting the acid tank car and even the produced water.

5.3. Accidents by Acid Leakage. The main causes of acid leakage are as follows: pipe fracture, unauthorized operation and carelessness, causing the pipe to break, corrosion cavity arising with the pipe not being painted in time, peeling of the anticorrosive layer, cavity formation in the wall surface due to stress cracks, and valve gasket cracking can be caused by inferior valve quality, uneven installation force, and wrong valve selection.

\section{Actions to Reduce the Impact of Failures}

6.1. Design of the Pipe End. For simultaneously preventing HLW reflux and addition of acid via pipelines, we can suspend the pipe into the liquid. This design directly avoids the liquid contact with the outside environment of the pipe, while circumventing the possibility of liquid flow into the acid- 
TABle 2: HAZOP analysis table.

\begin{tabular}{|c|c|c|c|c|}
\hline No. & Guide word & Deviation & Cause & Consequence \\
\hline 1 & Liquid level & $\begin{array}{l}\text { High liquid } \\
\text { level }\end{array}$ & The end of the acid pipe is inserted too deep into the liquid level & $\begin{array}{c}\text { Aerosol } \\
\text { extravasation }\end{array}$ \\
\hline 2 & Pressure & High pressure & $\begin{array}{l}\text { Add compressed air, abnormal air filter, abnormal high-pressure fan, and } \\
\text { positive pressure of storage tank }\end{array}$ & $\begin{array}{l}\text { Countercurrent } \\
\text { flow }\end{array}$ \\
\hline 3 & Temperature & $\begin{array}{c}\text { High } \\
\text { temperature }\end{array}$ & The waste liquid has high local temperature and evaporates too quickly & $\begin{array}{c}\text { Countercurrent } \\
\text { flow }\end{array}$ \\
\hline 4 & Stress & High stress & Illegal operation, carelessness, and material quality problem & Acid leakage \\
\hline
\end{tabular}

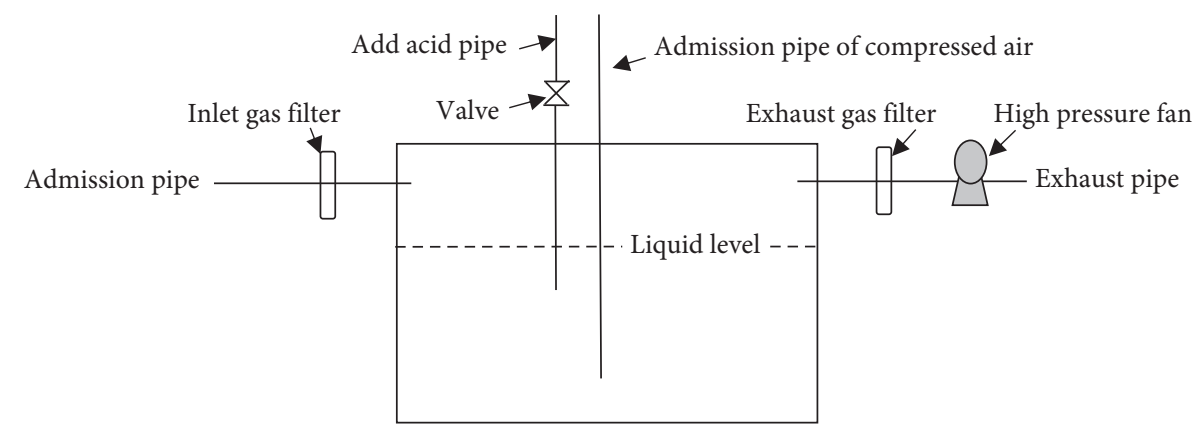

FIgURE 5: Schematic diagram of ventilation system for temporary acid adding process in storage tank.

containing pipelines with the liquid, while ensuring the contact of pipelines with pitcher comprising aerosols; therefore, even if HLW reflux and acid incorporation do occur, the severity of these processes will be considerably reduced.

We recognize the need for improving the pipelines that enter into the liquid (section FG), which has been achieved as follows: we create some grids of $40 \mathrm{~cm}$ from point $\mathrm{G}$ and made sure that it is interlinked with the outside gas, acid, and the tube wall in the tank that comprised grids; the phenomenon of contacting the surface by splashing can be improved. The dotted line FG represents the end of the improved pipe.

6.2. Design of the Check Valve. Here, we assumed that the check valve causes leakage and the sealing column of the U-shaped pipeline breaks down. Even if the liquid in the tank does not come in direct contact with the outside environment, the aerosol in the tank can, which will lead to the flow of aerosols along the pipeline into the acid tanker and the produced water.

6.3. Design of the Intermediate Trough. The intermediate trough can be used as a metering device for accurate measurement of the acid amount. The wall of the intermediate trough connects with the site of acid addition, and the top of the pipe contains a hole with a filter as the air inlet. We can overcome the resistance by controlling the height of the intermediate trough.

The schematic diagram of the improved system used for adding acid is shown in Figure 6:

First, let a certain amount of acid from the intermediate trough flow into the storage tank; second, we will add the produced water to intermediate trough for cleaning the intermediate trough and pipeline and then extract the water into the storage tank.

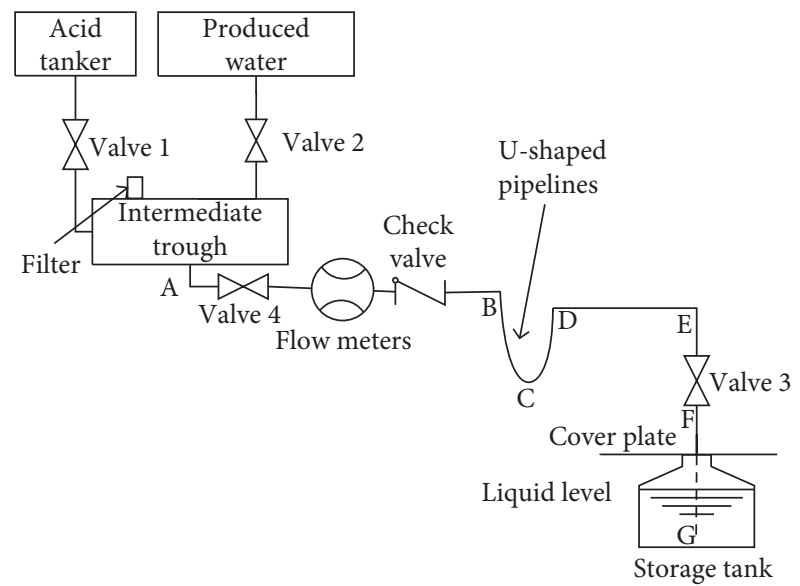

FIGURE 6: Schematic diagram of improving acid adding system for high-discharge waste liquid.

The cost associated with this method is relatively substantial; however, it isolates the radioactive aerosol containing storage tank with the produced water. In addition, valve 1 and valve 2 can also be used instead of the pipe joint for improved isolation.

Improving the pipe reduces the possibility of major accidents, while avoiding adverse issues caused by errors. Further, the acid content will not have a wide range of splash. Although an intermediate trough can reduce the possibility of polluting the produced water and acid tanker, using a filter can further reduce the possibility of aerosol pollution in the workplace.

\section{Conclusion}

Adding acid into HLWs is of great significance to ensure the safe storage of hazardous liquids. In this paper, the source and storage safety requirements of HLW are briefly 
introduced, and the risk analysis of the temporary acid adding system of HLW is carried out. We have assessed the risks associated with adding acid into HLW, which may cause accidents due to a countercurrent flow and damage the ecological environment. This study involves a safety analysis, while improving the current design used for storing HLWs. Overall, this paper is not aimed at improving a particular system. Through safety analyses and improvement of existing methods, this paper can provide insights into the addition of acids into HLWs.

Therefore, this paper adopts the HAZOP analysis method to analyze the accident sequence and cause of the major accidents that may occur in the high-level liquid waste storage tank and puts forward the corresponding system improvement ideas for these accidents, respectively, so as to ensure the safety of the acid adding system.

\section{Data Availability}

The data used to support the findings of this study are included within the article.

\section{Conflicts of Interest}

The authors declare that they have no conflicts of interest.

\section{Acknowledgments}

This article was supported by two projects, one is the Safety Treatment and Equipment Development of Decommissioning of Nuclear Facilities and Radioactive Leaks (no. 2012FJ1007) and the other one is Research on Key Technology of Nuclear Emergency Operation Robot (no. 2017JMH01). The authors want to thank their teacher and classmates for their help and thank the project team for aiding them.

\section{References}

[1] L. Quan, J. Wan, and J. Tu, "The development and research of high-level radioactive liquid waste management technology," High Technology Letters, no. 7, pp. 97-102, 2002.

[2] C. Wang, "The disposal of high-level radioactive waste," Science \& Technology Development, no. S1, p. 42, 2010.

[3] B. Sun, Technology Studies and Analyze Safety Store of HLLW of Certain Reprocessing Plant, p. 12, University of South China, Hengyang, Hunan, China, 2012.

[4] W. Luo, "Design, construction and inspection of high discharge waste liquid storage tank," Atomic Energy Science and Technology, vol. 27, no. 5, pp. 468-474, 1993.

[5] Y. Zhang and S. Lu, "The security measures of high-level radioactive liquid waste storage," The Progress Report of China's Nuclear Science and Technology, vol. 1, no. 11, pp. 71-74, 2009.

[6] Y. Zhao, Theory and Method of Safety Evaluation, pp. 56-61, China Coal Industry Publishing House, Beijing, China, second edition, 2015.

[7] Q. Tan, D. Miao, and J. Liu, "Research on the event tree analysis method based on reliability theory," Journal of Safety Science and Technology, vol. 11, no. 6, pp. 75-81, 2015.
[8] J. Zhou, C. Tang, and Z. Xu, "Event tree, fault tree, decisionmaking tree and Bayesian network," Journal of Hohai University (Natural Sciences), vol. 37, no. 3, pp. 351-355, 2009.

[9] H. Yu, "Several problems in the theory of event tree and its application," Industrial Safety and Environmental Protection, no. 13, pp. 18-22, 1994.

[10] L. Jin, H. Zhang, and L. Chen, Chemical Composition Analysis of High Effluent Liquid, China Institute of Atomic Energy, Beijing, China, 2000.

[11] Z. Xu, Safety Systems Engineering, pp. 73-74, China Machine Press, Beijing, China, 2012.

[12] Y. Hui, "Application of HAZOP in petrochemical design," Petrochemical Industry Technology, vol. 26, no. 10, pp. 66-67, 2019.

[13] Y. Zheng, S. Li, and Z. Liu, "HAZOP-based risk assessment of safety production of integrated circuit," Electric Engineering, no. 18, pp. 174-175, 2019.

[14] D. Gao, Y. Xiao, and B. Zhang, "HAZOP information standardization framework based on knowledge ontology," Chemical Industry and Engineering Progress, vol. 39, no. 6, pp. 2510-2518, 2020.

[15] B. Lin and J. Zhang, Safety Systems Engineering, pp. 32-33, China Labor Social Security Publishing House, Beijing, China, 2015.

[16] M. Chen, L. Qin, X. Yang, and P. Hu, "Risk analysis of RDX oxidation crystallization process based on HAZOP," Industrial Safety and Environment Protection, vol. 46, no. 12, pp. 11-13+60, 2020.

[17] Z. Shen, "Method to treatment and disposal HLW," Radiation Protection Bulletin, vol. 22, no. 1, pp. 37-39, 2002.

[18] S. Luo, Radioactive Waste Treatment and Disposal, vol. 6, pp. 61-62, China Environmental Press, Beijing, China, 2007.

[19] F. Song, D. Lv, and J. Que, "Analysis on the main safety problems of treatment systems of high level liquid wastes and organic solvent wastes in nuclear fuel reprocessing plant," Nuclear Science and Engineering, vol. 35, no. 2, pp. 320-327, 2015.

[20] J. Hao, "Status of spent nuclear materials and high-level waste disposal plans in the world," Radiation Protection Bulletin, no. 1, p. 39, 2003.

[21] Y. Liao, H. Yun, and C. Wang, "A survey of research on reprocessing technology of spent nuclear fuel's," Sichuan Chemical Industry, vol. 15, no. 4, pp. 12-15, 2012.

[22] S. Jiang and F. Ren, Nuclear Fuel Reprocessing Engineering, pp. 473-474, China Atomic Energy Press, Beijing, China, 1995. 